\title{
Ocorrência de Calotropis procera (Ait.) R. Br. (Apocynaceae) como espécie invasora de restinga
}

\author{
Elisangela de Sousa Rangel ${ }^{1}$ e Marcelo Trindade Nascimento ${ }^{1,2}$
}

Recebido em 6/05/2010. Aceito em 29/06/2011

\begin{abstract}
RESUMO
(Ocorrência de Calotropis procera (Ait.) R. Br. (Apocynaceae) como espécie invasora de restinga). Apesar de possuírem grande importância ao nível de conservação ambiental, existe no Brasil uma acentuada escassez de trabalhos relacionados às invasões biológicas em ambientes terrestres. As restingas, sobretudo, são ambientes extremamente susceptíveis a este tipo de ameaça. Este estudo teve como objetivo avaliar a ocorrência e a estrutura populacional da espécie exótica Calotropis procera na Restinga do Xexé, Farol de São Thomé, Campos dos Goytacazes, RJ. Uma varredura que abrangeu uma área de 126 ha ( $1400 \mathrm{~m}$ x 900m) foi realizada, sendo amostrado um total de 475 indivíduos, ou seja, uma média de 3,8 indivíduos por hectare. Para a avaliação da distribuição dos indivíduos num gradiente interior-praia, foram alocados três transectos $(300 \mathrm{~m} \times 10 \mathrm{~m})$ nesta direção. A amostragem nos transectos indicou a ocorrência de 28 indivíduos com altura $>50 \mathrm{~cm}$ e nenhum com altura $\leq 50 \mathrm{~cm}$, sendo sua ocorrência restrita as áreas com vestígios de perturbação e não tendo sido constatado nenhuma relação com a distância da praia. A ausência de plântulas e jovens na amostragem ao longo dos transectos sugere o rápido desenvolvimento dos indivíduos após a germinação. Os resultados indicaram que Calotropis procera possui grande potencial invasor de áreas perturbadas de restinga. Um plano de ações para seu controle e erradicação deve ser urgentemente implementado pelos órgãos ambientais responsáveis.
\end{abstract}

Palavras-chave: algodão da praia, espécie exótica, espécie introduzida, vegetação costeira

\begin{abstract}
(Occurrence of Calotropis procera (Ait.) R. Br. (Apocynaceae) as an invasive species in restinga vegetation). Although invasive species are one of the main reasons for the loss of biodiversity, in Brazil there is little information about biological invasions in terrestrial ecosystems. Sandy coastal plain forests (restinga) and shrubby vegetation are places extremely susceptible to this kind of threat. The goal of this work was to evaluate the occurrence of the exotic species Calotropis procera in the Restinga do Xexé, Farol de São Tomé, Campos dos Goytacazes, RJ, Brazil. A survey covering an area of $126 \mathrm{ha}(1400 \mathrm{~m} \mathrm{x} 900 \mathrm{~m}$ ) was carried out, where a total of 475 individuals were sampled (mean of 3.8 indiv.ha $\left.{ }^{-1}\right)$. To assess the spatial distribution and population structure of this species, three transects $(300 \mathrm{~m} \mathrm{x} 10 \mathrm{~m})$ were created, which were perpendicular to the vegetation gradient from interior to shoreline, and all individuals of C. procera were sampled. A total of 28 individuals $>50 \mathrm{~cm}$ tall were sampled, and no individuals $<50 \mathrm{~cm}$ tall were found in the three transects. The plants were restricted to areas with vestiges of human disturbance. The absence of seedling samples within the transects is probably related to the fast growth of this species after germination. The results showed that C. procera has a great potential of invading disturbed areas in restinga vegetation. A plan to control and eradicate this species should be considered by the Brazilian environmental agency.
\end{abstract}

Key words: coastal vegetation, exotic species, invasive species, rooster tree

\section{Introdução}

A maior parte da biodiversidade global está inserida na região tropical. Região esta que vem sofrendo diferentes formas de intervenções humanas tais como desmatamento, queimadas, caça, introdução de espécies exóticas, entre outros. As invasões biológicas são atualmente consideradas como a segunda maior ameaça à biodiversidade ambiental, perdendo apenas para a destruição de habitats pela exploração humana direta (Instituto Horus 2008). No contexto brasileiro, de acordo com a Portaria IAP (Instituto Ambiental do Pará 2007), as espécies exóticas invasoras produzem mudanças e alterações nas propriedades ecológicas do solo, na ciclagem de nutrientes, nas cadeias tróficas, na estrutura, dominância, distribuição e funções de um dado ecossistema, na distribuição da biomassa, na taxa de decomposição, nos

1 Universidade Estadual do Norte Fluminense Darcy Ribeiro, Laboratório de Ciências Ambientais, Campos dos Goytacazes, RJ, Brasil

2 Autor para correspondência: mtn@uenf.br 
processos evolutivos e nas relações entre polinizadores. Neste sentido o termo contaminação biológica refere-se aos danos causados por espécies que não fazem parte, naturalmente, de um dado ecossistema, mas que se naturalizam, passam a se dispersar e provocam mudanças em seu funcionamento, não permitindo sua recuperação natural (Ziller 2001). Segundo Barbieri \& Melo (2006) a introdução de espécies exóticas encontra-se tipicamente vinculada às atividades de interesse socio-econômico.

Planícies costeiras arenosas e tipos vegetacionais associados ao bioma Mata Atlântica encontrados ao longo da costa brasileira representam um ecossistema bastante diversificado em fisionomia, florística e estrutura (Assis et al. 2004). Estas planícies litorâneas incluem áreas representativas de diferentes unidades fitoecológicas, como a Floresta Ombrófila Densa de Terras Baixas (região da Floresta Ombrófila Densa) e as Formações Pioneiras com Influência Marinha, Flúvio-marinha ou Fluvial/lacustre (sistemas edáficos de primeira ocupação) (Veloso et al. 1991). Formações pioneiras estas, que compõe um tipo vegetacional exuberante e diversificado, denominado restinga que, geomorfologicamente, corresponde ao resultado de mudanças quaternárias no nível do mar (Martin et al. 1993). Assis et al. (2004) salientam o fato de que a maioria absoluta das espécies da restinga ocorre na Mata Atlântica, o que justifica a inclusão deste ecossistema nos projetos de conservação e manejo da Mata Atlântica. Segundo Scherer et al. (2005), entre os ecossistemas brasileiros, o de restinga é um dos mais impactados e estudos que retratem o estado de conservação destes ambientes são de grande importância. Entretanto, poucos são os estudos que abordam a ocorrência de espécies exóticas e/ou invasoras em ambiente de restinga. Entre eles, podemos destacar os de Ziller \& Galvão (2003), Sanches et al. (2007) e CEPAN (2009). Estes estudos demonstraram a ocorrência do pinheiro (Pinus elliotti Engel. e $P$. taeda L.) da amendoeira (Terminalia catappa L.) e da casuarina (Casuarina equisetifolia L.) como exóticas invasoras em áreas de restinga no Brasil.

No norte fluminense tem sido observada a ocorrência da espécie exótica, Calotropis procera (Ait.) R. Br. (Apocynaceae), em áreas litotâneas. Esta planta ocorre naturalmente na África e Ásia (Brandes 2005), e possui hoje uma ampla distribuição geográfica, se disseminando com muita facilidade por regiões áridas e semi-áridas onde a dispersão é favorecida por apresentar sementes aladas envolta por uma plumagem que facilita seu transporte pelo vento (Joly 1997; Souto et al. 2008), sendo comum na região nordeste do Brasil. Sua introdução, em 1900, no Estado do Recife, teve objetivos inicialmente ornamentais (Instituto Horus 2008), porém hoje outras atividades econômicas são conhecidamente atribuídas à utilização deste arbustos a produção de ração e extração de madeira para lenha, por exemplo, são algumas das atividades descritas na literatura (Abbas et al. 1992, Barbosa et al. 2007, Andrade et al. 2008, Souto et al. 2008).
Calotropis procera é um arbusto popularmente conhecido por ciumeira ou saco de velho, produz grande quantidade de látex, que é facilmente coletado de suas partes quando a planta sofre algum dano. $\mathrm{O}$ aspecto de sua secreção natural lembra a secreção da árvore da borracha Hevea brasiliensis (Willd.ex Adr.Juss.) Müll.Arg. (Euphorbiaceae). A abundância de látex nas partes verdes da planta reforça a idéia de que o látex é produzido e acumulado como uma estratégia de defesa contra organismos como, por exemplo, fungos e insetos (Larhsini et al.1997). Trabalhos de cunho ecológico para esta planta são escassos, a grande maioria dos estudos visa às propriedades químicas de seu látex (Fleurentin e Pelt, 1982; Akinloye et al. 2001; Ramos et al. 2006 e Oliveira et al. 2009).

Considerada uma espécie ruderal, esta planta ocupa áreas modificadas pelo homem. No entanto, seu rápido estabelecimento, formando densamentos, faz com que ela seja considerada como uma invasora, freqüentemente dominante em áreas abandonadas e/ou degradadas física e quimicamente, assumindo um papel de planta indicadora desse tipo de perturbação (Souto et al. 2008; CEPAN 2009). C. procera é dotada de crescimento rápido, requerendo apenas 90 dias após sua germinação para alcançar altura superior à $50 \mathrm{~cm}$ e produzir suas primeiras flores, sendo classificado portanto como adulto reprodutivo (Andrade et al. 2005).

Este trabalho teve por objetivo determinar a ocorrência e a estrutura populacional de Calotropis procera na Restinga do Xexé, Farol de São Tomé, Campos dos Goytacazes, RJ, com o intuito de avaliar seu potencial invasor na região e fornecer subsídio para a elaboração de um plano de manejo para a erradicação desta espécie na região.

\section{Material e métodos}

\section{Área de estudo}

O trabalho foi desenvolvido na restinga do Xexé localizada no distrito de Farol de São Tomé, litoral do município de Campos dos Goytacazes, região Norte do Estado do Rio de Janeiro (Fig 1). O clima predominante na região é o tropical úmido, apresentando duas estações, uma seca (inverno) e outra chuvosa (verão), além de uma precipitação anual média variando de 800 a $1.200 \mathrm{~mm}$ (Assumpção \& Nascimento 2000).

Esta restinga ocupa uma área pouco estudada em seu aspecto florístico e ecológico, sendo um dos últimos remanescente de restinga do município de Campos, RJ. Dados de diversidade e/ou abundância de espécies para o local ainda são raros. Um levantamento florístico realizado em 2008 na região revelou a ocorrência de 40 famílias de plantas. O mesmo estudo apontou para a presença de três unidades fisionômicas, nesta região, na direção do mar para o interior, sendo elas: Formação Praial Graminóide, Formação Praial com Moitas e Formação de Mata de Restinga (Mazurec et al. 2008). 


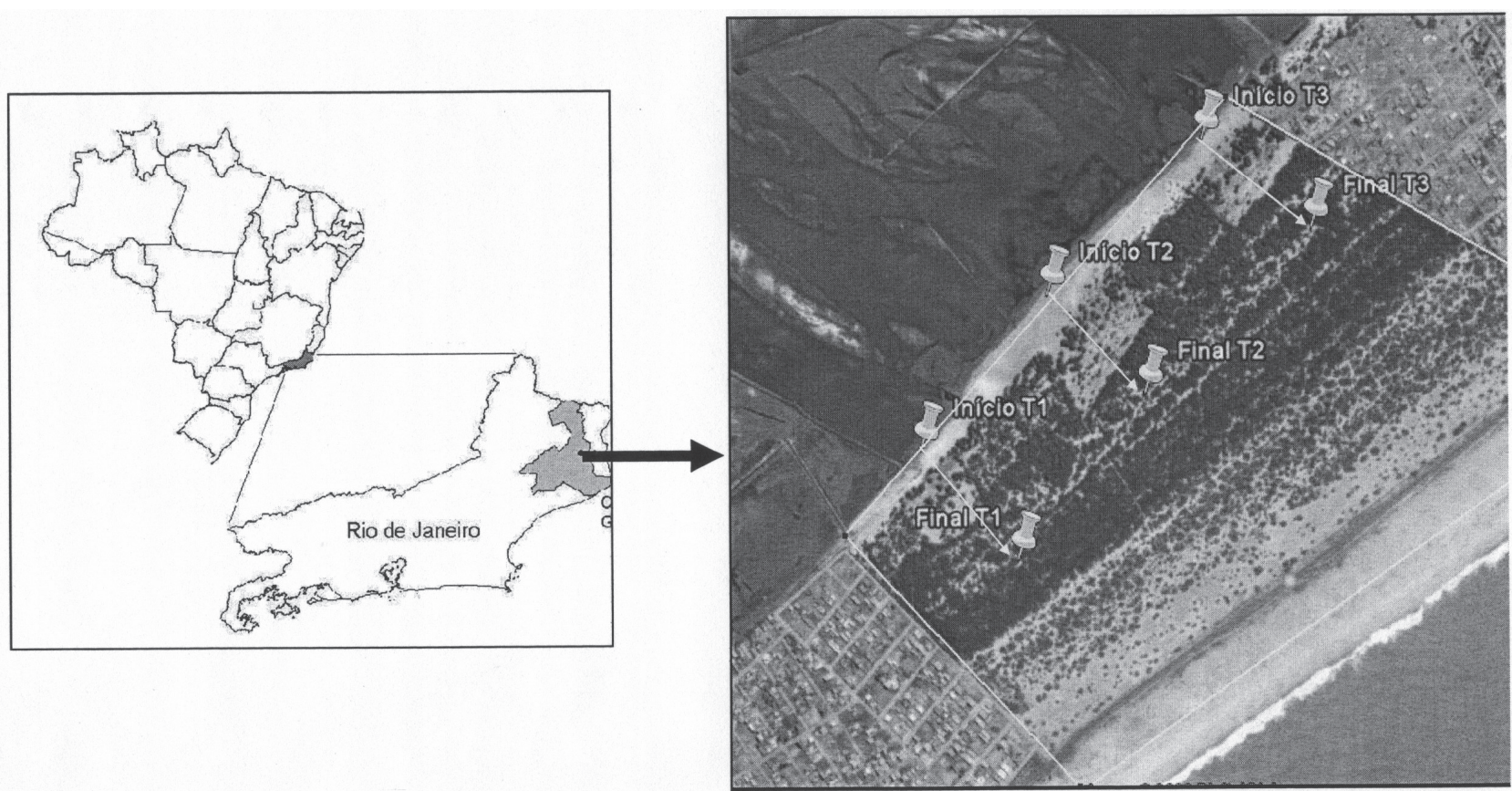

Figura 1. Localização da área de estudo, evidenciando os transectos (setas) e área de varredura (delimitação em linha branca), na restinga do Xexé, Farol de São Tomé, Campos dos Goytacazes, RJ. Fonte: Google Earth.

\section{Metodologia de Amostragem}

As primeiras visitas à região foram realizadas em janeiro de 2008 onde varreduras visando o registro de Calotropis procera foram realizadas. Estas varreduras abrangeram uma área de 126 ha (1400m x 900m) (Fig 1) e todos os indivíduos encontrados de $C$. procera com altura superior à $50 \mathrm{~cm}$ foram marcados com auxílio de um GPS.

Para a avaliação da distribuição de C. procera ao longo de um gradiente de distância da linha da maré, foram alocados três transectos de forma perpendicular à linha da costa. Todos com início na região próxima a um brejo distante cerca de $900 \mathrm{~m}$ da praia e adentrando $300 \mathrm{~m}$ em direção ao mar, com uma largura de $10 \mathrm{~m}$. De forma a abranger faixas abertas e fechadas da restinga, um transecto foi alocado no início, outro no meio e um terceiro no final da área de varredura, com distância de c. $400 \mathrm{~m}$ um do outro (Fig.1).

A cada $10 \mathrm{~m}$ do transecto foi estabelecido um ponto de coleta, totalizando 30 pontos. Afim de garantir a aleatoriedade das coletas foram sorteados o lado do ponto (esquerdo ou direito) a ser alocada uma parcela de $5 \mathrm{~m} \mathrm{x} 5 \mathrm{~m}$ objetivando à amostragem dos indivíduos jovens (plantas com altura total superior à $10 \mathrm{~cm}$ e inferior à $50 \mathrm{~cm})$ e adultos $(>50$ $\mathrm{cm}$ de altura). Já em relação às plântulas (indivíduos com até $10 \mathrm{~cm}$ de altura), parcelas de $1 \mathrm{~m} \times 1 \mathrm{~m}$ foram alocadas dentro dos quadrados de $5 \mathrm{~m} \times 5 \mathrm{~m}$ de forma sistemática, sempre em no canto esquerdo do mesmo. Em cada ponto de coleta todos os indivíduos de C. procera encontrados foram medidos quanto ao comprimento total, diâmetro na base (DAB) e diâmetro à altura do peito (DAP).

Para comparação da densidade média de indivíduos de C. procera entre os transectos foi utilizado o teste de
Mann -Whitney (U) em nível de significância de 95\% (Zar 1984).

\section{Resultados}

O levantamento dos indivíduos de C. procera pelo método de varredura totalizou 475 indivíduos nos 126 ha amostrados, ou seja, uma média de 3,8 indivíduos ha-1. Entretanto, como pode ser observado na figura 2 sua distribuição não é uniforme, se concentrando em alguns trechos da área demarcada. Nenhum indivíduo foi observado na região que abrange moitas ou áreas de vegetação mais densa.

Em relação à amostragem nos três transectos, um total de 28 indivíduos foi registrado, sendo que a média de indivíduos amostrados por parcela $\left(25 \mathrm{~m}^{2}\right)$ para o transecto 1 foi de 0,4 indivíduos (Tab.1). Este transecto contribuiu com 12 indivíduos para o total amostral, apresentando o maior número de exemplares de C.procera. O segundo transecto ocupou a segunda colocação em número de indivíduos, onde foram amostrados 9 plantas, com uma média de 0,3 indivíduos por parcela. No transecto 3 ocorreram apenas 7 indivíduos nas 30 parcelas amostradas (Tab.1), uma média de 0,23 indivíduos por parcela.

A representação gráfica da distribuição dos indivíduos de C. procera (Fig. 3) indica que os indivíduos do transecto 1 ocupavam, em sua maioria, os primeiros $100 \mathrm{~m}$ do transecto. No transecto 2 as plantas amostradas estavam localizadas do meio para o final do mesmo (entre 140 e 240 m). Já no transecto 3 seus indivíduos estavam mais concentrados na parte intermediária do transecto (entre 120 e $210 \mathrm{~m}$ ). Ou seja, sua distribuição ao longo do transecto parece não possuir uma relação direta com a distância do mar. 


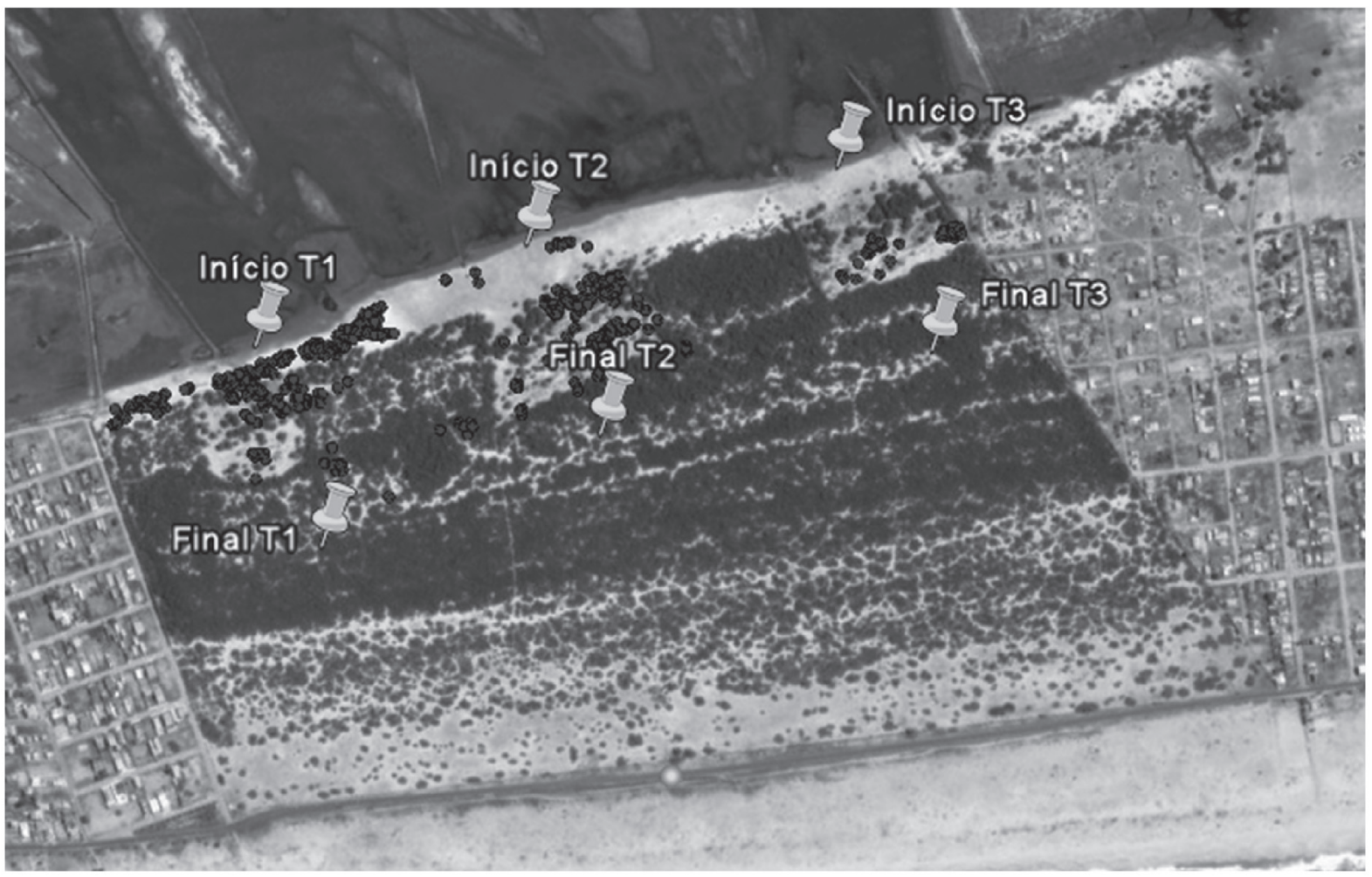

Figura 2. Transectos e pontos representando os indivíduos de Calotropis procera registrados nos 126 há amostrados na Restinga do Xexé, Farol de São Tomé, Campos dos Goytacazes, RJ.. Fonte: Google Earth.

Os valores encontrados para densidade não diferiram significativamente entre os transectos estudados $(U=433,0$; $p=0,8015)$, embora tenha ocorrido uma tendência do transecto 1 apresentar um maior número de indivíduos .

A maioria dos indivíduos amostrados apresentou múltiplos troncos (indivíduos perfilhados). No transecto 1 do total de 12 indivíduos amostrados, oito eram perfilhados, o que representa $67 \%$ do total de indivíduos amostrados. O transecto 2 teve um total de nove indivíduos amostrados, sendo quatro deles perfilhados (44\%). Enquanto o transecto 3 apresentou um número total de sete indivíduos, dos quais 4 eram perfilhados.

A altura máxima dos indivíduos de C. procera na restinga do Xexé foi de 4,5 m (Fig. 4). O transecto 2 teve em sua maioria indivíduos menores (até $1,5 \mathrm{~m}$ ), enquanto que o transecto 3 foi o único transecto, onde a presença de indivíduos de mais de $4 \mathrm{~m}$ foi observada. O primeiro transecto diferentemente dos outros, apresentou a maioria de seus indivíduos distribuídos na classe de altura entre 2,6 e 3,5 m.

A distribuição diamétrica dos indivíduos amostrados (Fig. 5) indicou que as plantas do transecto 1 apresentaram valores bastante variados, em sua maioria entre 6 e $17 \mathrm{~cm}$. Sendo que o DAB máximo (Tab.1) encontrado foi de $16 \mathrm{~cm}$. Os transectos 2 e 3 teveram a maioria de seus indivíduos com valores de diâmetro entre 6 e $11 \mathrm{~cm}$. No transecto 3 , foi registrado o indivíduo com tronco de maior calibre (18 $\mathrm{cm}$ de DAB).

\section{Discussão}

A ocorrência de Calotropis procera na vegetação de restinga de forma agrupada e em áreas abertas e com evidências de perturbação, tais como retirada parcial da vegetação, pisoteio por gado e vestígio de fogo corrobora com dados da literatura que citam esta espécie como um arbusto preferencialmente de áreas abertas e/ou abandonadas (Melo et al. 2001; Souto et al. 2008).

A presença do gado e, assim, o pastoreio por parte destes animais sobre C. procera é uma variável a ser considerada, visto que a ocorrência destes animais pode estar interferindo nas taxas de crescimento e mortalidade da espécie. O pastoreio e/ou pisoteio de C.procera por gado é algo que requer estudos mais detalhados, visto que durante as coletas de campo foram observados plantas com sinais de danos em suas folhas por animais de grande porte. Depoimentos provenientes da população local atribuem óbitos de gados associados a pastoreio do gado no algodão da praia. De acordo com a literatura esta planta é tóxica tanto para o gado quanto para o homem ( Ulhôa et al. 2007).

Segundo Brandes (2005), a altura máxima encontrada para C.procera reportada na literatura é de $5,5 \mathrm{~m}$ enquanto a circunferência máxima gira em torno de $57,5 \mathrm{~cm}$. Nosso estudo apontou para a presença de indivíduos relativamente menores, com altura máxima de $4,5 \mathrm{~m}$, porém com valor de circunferência máxima muito similar à citada na literatura (circunferência máxima encontrada $57 \mathrm{~cm}$ ). 
Tabela 1. Número médio de indivíduos por parcela, distribuição dos indivíduos em metros nos transectos (300 m), diâmetro à altura da base (DAB) médio e máximo por transecto dos indivíduos amostrados na restinga do Xexé, Farol de São Tomé, Campos dos Goytacazes, RJ.

\begin{tabular}{|c|c|c|c|c|}
\hline Transectos & $\mathrm{N}^{\circ}$ médio de indivíduos por parcela $\left(25 \mathrm{~m}^{2}\right)$ & Distribuição dos indivíduos no transecto & DAB médio & DAB máximo \\
\hline 1 & 0,40 & Até $180 \mathrm{~m}$ & 8,3 & 16 \\
\hline 2 & 0,30 & Entre 150 e $250 \mathrm{~m}$ & 8,3 & 16 \\
\hline 3 & 0,23 & Entre 120 e $210 \mathrm{~m}$ & 10 & 18 \\
\hline
\end{tabular}

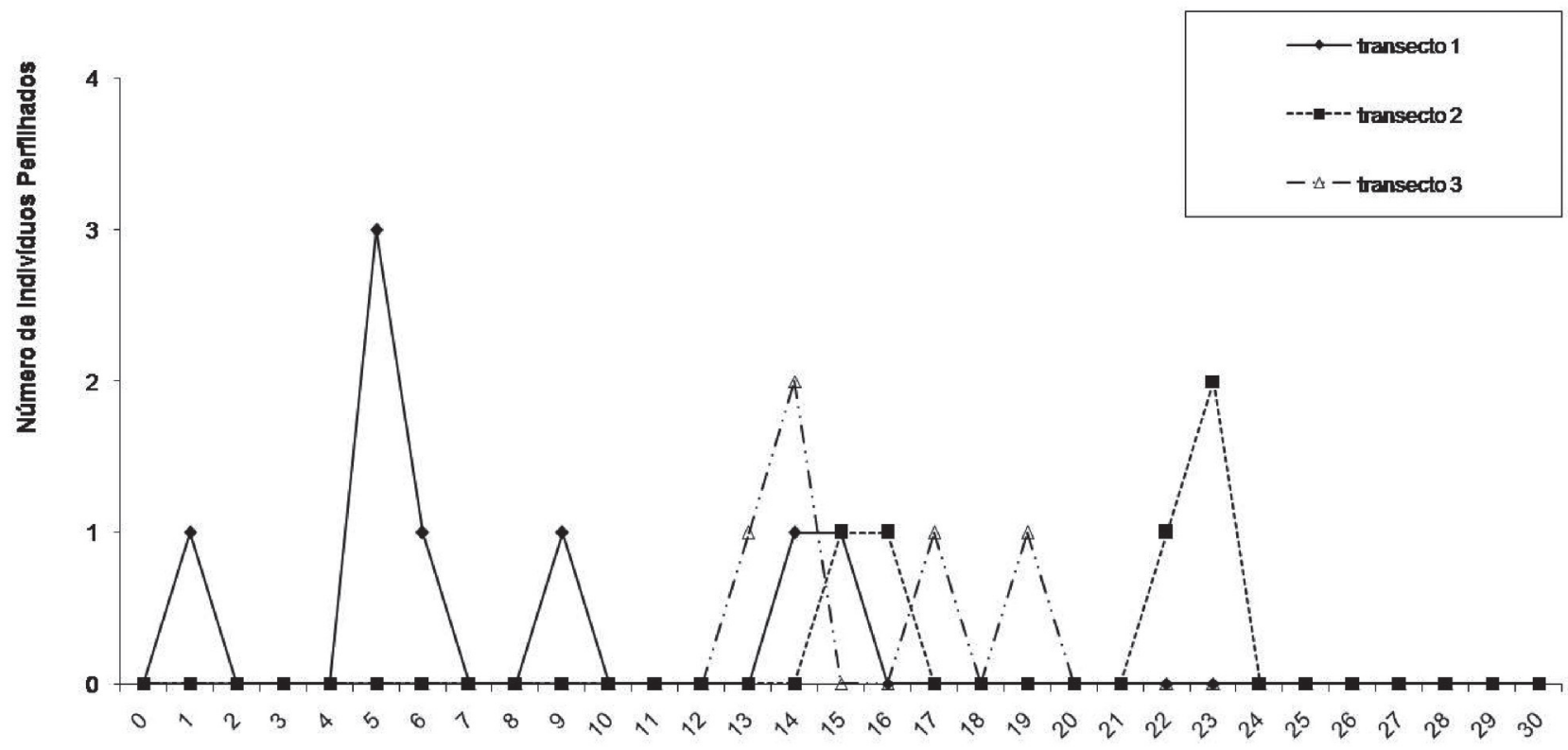

Parcelas

Figura 3. Número de indivíduos amostrados de Calotropis. procera por parcela em cada um dos transectos amostrados na restinga do Xexé, Farol de São Tomé, Campos dos Goytacazes, RJ.

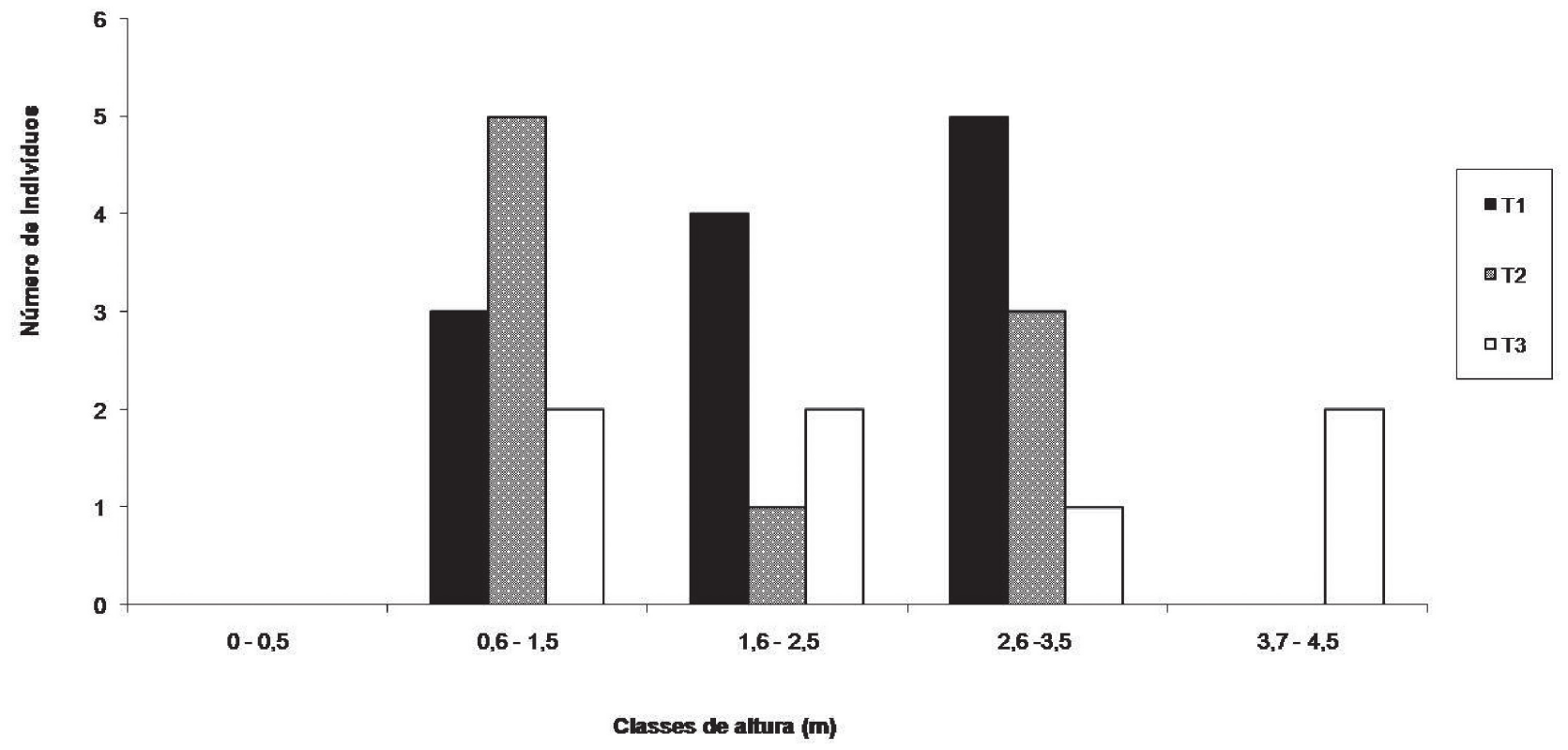

Figura 4. Classe de altura dos indivíduos amostrados em cada um dos transectos, na restinga do Xexé, Farol de São Tomé, Campos dos Goytacazes, RJ. 


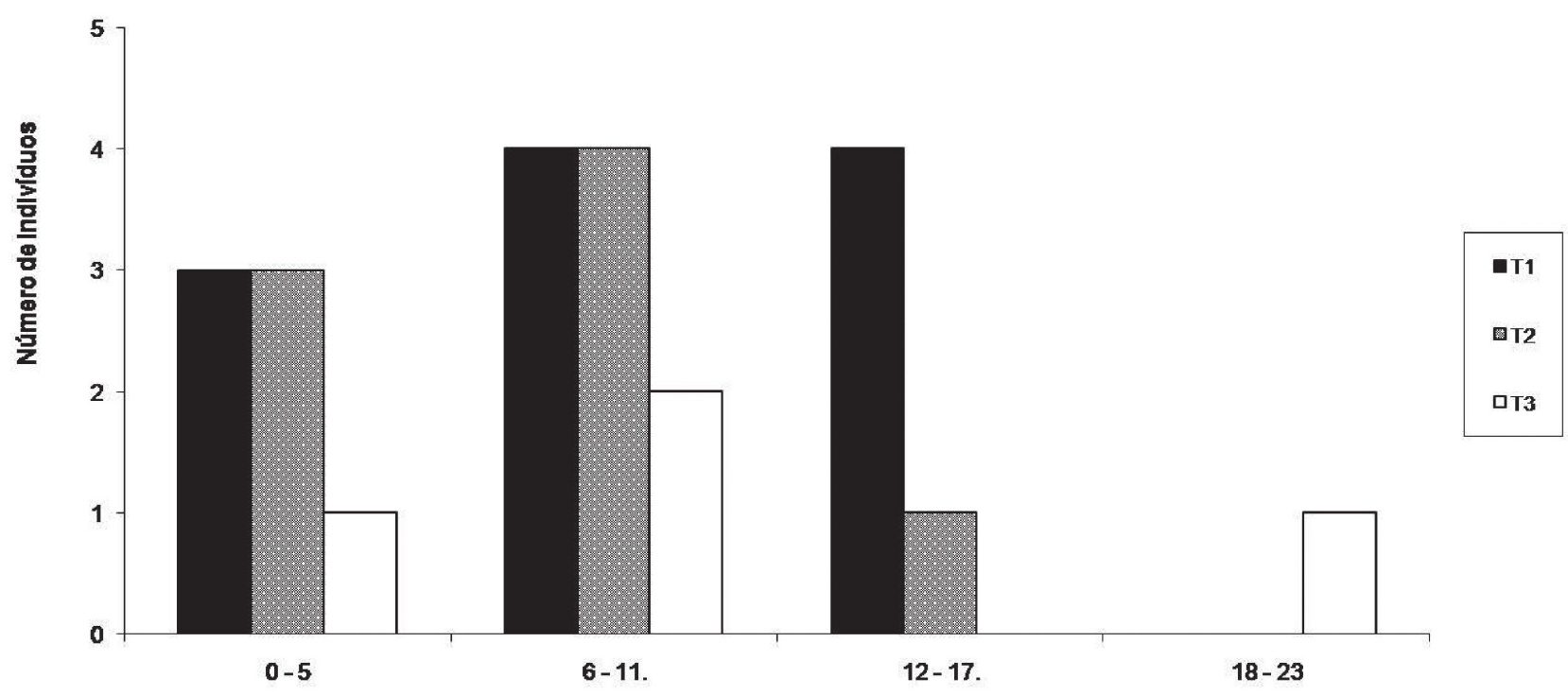

Classe de dīâmetro na base (cm)

Figura 5. Classe de diâmetro dos indivíduos amostrados em cada um dos transectos, na restinga do Xexé, Farol de São Tomé, Campos dos Goytacazes, RJ.

A restinga da praia do Farol de São Tomé, principalmente na região do Xexé, possui um histórico de perturbação muito pronunciado. $\mathrm{O}$ tamanho reduzido e a extração não sustentável de recursos naturais são fatores complicadores à regeneração desta restinga. O potencial de rebrota, que segundo alguns autores (Sá 1996; Carvalhaes \& Mantovani 1998; Assumpção \& Nascimento 2001) várias espécies de restinga possuem, pode ser um fator chave ao processo de estabelecimento de algumas espécies neste ambiente. C.procera também possui poder de rebrota, e isso pode ser evidenciado através dos altos índices de indivíduos perfilhados encontrados ao longo dos transectos. Fato este, que pode possibilitar o sucesso no estabelecimento desta espécie em locais perturbados.

A ausência de plântulas na amostragem dos transectos em janeiro de 2008 parece estar relacionada ao seu rápido desenvolvimento, atingindo mais de $50 \mathrm{~cm}$ em apenas 90 dias (Andrade et al. 2005). Registros do Herbário UENF apontam para um período de floração em dois picos um em maio-junho e outro em outubro-dezembro, estando assim em janeiro com frutos verdes.

A aparente eficiência da síndrome dispersiva (anemocoria), o mecanismo de regeneração facilitado pelo poder de rebrota acentuado e o bom desempenho desta espécie em local perturbado são características de vida que contribuem para o potencial invasor que esta planta exótica aparenta ter.

Para um entendimento mais aprofundado sobre o potencial invasor de C. procera em ambientes naturais é necessário o desenvolvimento de estudos detalhados acerca das interações entre esta planta $\mathrm{e}$ as populações animais e vegetais presentes. O que é altamente requerido para fins de elaboração de plano de manejo para esta espécie em áreas de restinga.
Na restinga do Farol de São Tomé C. procera se encontra restrita à áreas abertas e impactadas, não ocorrendo em faixas preservadas. Os mecanismos facilitadores à sua dispersão indicam que estas áreas preservadas uma vez perturbadas serão locais susceptíveis ao estabelecimento desta planta. Portanto, políticas públicas de interferência visando controlar essa planta na região e ações de fiscalização para minimizar a ação antrópica nesta área são tão imprescindíveis, quanto urgentes.

\section{Agradecimentos}

À Fenorte/Tecnorte pela concessão de bolsa ao primeiro autor e ao CNPq pela bolsa de produtividade em pesquisa a Marcelo Trindade Nascimento. À Alex Masurec, Marcela Matella Fraga e Andreia Almeida pelo apoio no campo e pelas valiosas sugestões para a realização deste trabalho.

\section{Referências}

Abbas, B.A.E.; Tayeb, E.; Sulleiman, Y.R. 1992. Calotropis procera: feed potential for arid zones. Veterinary Record 131(6):132.

Andrade, M.V.M.; Silva, D.D.; Andrade, A.P.; Medeiros, A.N. \& Pinto, M.S.C. 2005. Fenologia da Calotropis procera Ait R.Br., em função do sistema e da densidade de plantio. Archivos de Zootecnia 54(208): 632.

Andrade, M.V.M.; Silva, D.S.; Andrade, A.P.; Medeiros, A.N.; Pimenta Filho, E.C.; Cândido, M.J.D. \& Pinto, M.S.C. 2008. Produtividade e qualidade da flor-de-seda em diferentes densidades e sistemas de plantio. Revista Brasileira de Zootecnia 37: 1-8.

Akinloye, A.K.; Abatan, M.O.; Onwuka, S.K.; Alaka, O.O. \& Oke, O.O. 2001. Lipolytic effect of Calotropis procera in the skin of wistar rats. African Journal of Biomedical Ressearch (4): 143- 145. 
Assis, A.M.; Thomaz, L.D. \& Pereira, O.J. 2004. Florística de um trecho de floresta de restinga no município de Guarapari, Espírito Santo, Brasil. Acta Botanica Brasilica 18(1): 191-201.

Assumpção, J. \& Nascimento M. T. 2000. Estrutura e composição florística de quatro formações vegetais de restinga no complexo lagunar Grussaí/ Iquipari, São João da Barra, RJ, Brasil. Acta Botanica Brasilica 14(3): 301-315.

Barbosa, N.P.U.; Almeida-Cortez, J.S. \& Fernandes, G.W. 2007. Uma estranha na paisagem. Ciência Hoje 41: 70-72.

Barbieri, E. \& Melo, G.A.S. 2006. Biodiversidade: ocorrência da espécie exótica Litopenaeus Vannamei (Boone, 1931) no complexo estuarinolagunar de Cananéia-Iguape-Ilha Comprida. O mundo da Saúde São Paulo: 30(4): 654-659.

Brandes, D. 2005. Calotropis procera on Fuerteventura. Germany, Technical University Braunschweig.

Carvalhães, M.A. \& Mantovani, W. 1998. Florística de mata sobre restinga na Juréia, Iguape-SP. Pp. 37-48. In: Anais do IV Simpósio de Ecossistemas Brasileiros. São Paulo, ACIESP v.2.

Cepan, 2009. Contextualização sobre Espécies Exóticas Invasoras. Dossiê Pernambuco. Recife, Centro de Pesquisas Ambientais do Nordeste.

Fleurentin, J. \& Pelt, J.M. 1982. Repertory of drugs and Medicinal plants of Yemen J. Ethnopharmacol 5: 85-108.

INSTITUTO HÓRUS - Instituto Hórus de Desenvolvimento e Conservação Ambiental. The Nature Conservancy, www.institutohorus.org.br (Acesso em maio de 2008).

Joly, A. B. 1997. Botânica - Introdução à taxonomia vegetal. 5 ed. São Paulo, Ed Nacional.

Larhsini, M.; Bousaid, M.; Lazrek, H.B.; Jana, M. \& Amarouch, H. 1997. Evaluation of antifungal and molluscicidal properties of extracts of Calotropis procera. Fitoterapia 68: 371-373.

Martin, L.; Suguio, K \& Flexor, J.M. 1993. As flutuações de nível do mar durante o quaternário superior e a evolução geológica de "deltas" brasileiras. Boletim do Instituto de Geologia-USP 15 (Publicação Especial): 1-186.

Mazurec, A.P.; Thomé, M.M.; Nogueira, M.R.; Lima, L.M.; Fraga, M.M.A.C.; Bernini, E.; Raphael, D.M.L. \& Rangel, E.S. 2008. Diagnóstico de Ecossistemas Interessantes para Ampliação do Número de Unidades de Conservação em Campos dos Goytacazes, RJ: Restinga do Xexé. Goiânia, Instituto Goitacá de Estudos Sócio Ambientais.
Melo, M.M.; Vaz, F.A.; Gonçalves, L.C. \& Saturnino, H.M. 2001. Estudo fitoquímico da Calotropis procera Ait., sua utilização na alimentação de caprinos: efeitos clínicos e bioquímicos séricos. Revista Brasileira de Saúde Produção Animal 2: 1520.

Oliveira S.H.F.; Negreiros D.; Fernandes G.W.; Barbosa N.P.U.; Rocha R. \& Almeida-Cortêz J.S. 2009. Seedling growth of the invader Calotropis procera in ironstone rupestrian field and seasonally dry forest soils. Neotropical Biology and Conservation 4: 69-76.

PORTARIA IAP (Instituto Ambiental do Paraná) de 19 de abril de 2007. Lista Oficial de Espécies Exóticas Invasoras para o Estado do Paraná, $\mathrm{n}^{\circ} 074$

Ramos, M.V.; Bandeira, G. de P.; de Freitas, C.D.T.; Nogueira, N.A.P.; Alencar, N.M.N.; de Sousa, P.A.S. \& Carvalho, A.F.U. 2006. Latex constituents from Calotropis procera (R. Br.) display toxicity upon egg hatching and larvae of Aedes aegypti (Linn.). Memórias do Instituto Oswaldo Cruz, Rio de Janeiro 101(5): 503-510.

Sá, C.F.C. 1996. Regeneração em área de floresta de restinga na Reserva Ecológica Estadual de Jacarepiá, Saquarema-RJ: I - Estrato herbáceo. Arquivos do Jardim Botânico do Rio de Janeiro 34(1): 177-192.

Sanches, J.H.; Magro, T.C. \& da Silva, D.F. 2007. Distribuição espacial da Terminalia catappa L. em área de restinga no Parque Estadual da Serra do Mar, Núcleo Picinguaba, Ubatuba/SP. Pp. 1831-1838. In: Anais XIII Simpósio Brasileiro de Sensoriamento Remoto. Florianópolis, INPE.

Scherer, A.; Maraschin-Silva, F. \& Baptista, L.R.M. 2005. Florística e estrutura do componente arbóreo de matas de Restinga arenosa no Parque Estadual de Itapuã, RS, Brasil. Acta Botanica Brasilica 19(4): 717-726.

Souto, P.C.; Sales, S.C.V.; Souto, J.S.; Santos, R.V. \& Sousa, A.A. 2008. Biometria de Frutos e Número de Sementes de Calotropis procera (Ait.) R. Br no Semi-Àrido da Paraíba. Revista Verde 3: 108113.

Veloso, H.P., Rangel Filho, A.L. \& Lima, J.C.A. 1991. Classificação da vegetação brasileira, adaptada a um sistema universal. Rio de Janeiro, IBGE.

Ziller, S.R. 2001. Plantas exóticas invasoras: a ameaça da contaminação biológica. Ciência Hoje 30(178): 77-79.

Ziller, S.R \& Galvão, F. 2003. A degradação da estepe gramíneo-lenhosa no paraná por contaminação biológica de Pinus elliotti e P. taeda. Revista Floresta 32(1): 41-47. 